\title{
Use of Magnetic Barkhausen Noise (MBN) to Follow Up the Formation of Sigma Phase in Saf2205 (UNS S31803) Duplex Stainless Steel
}

\author{
Edgar Apaza Huallpa ${ }^{a, d * *}$ Eduardo Franco de Monlevade ${ }^{a}$, Julio Capó Sánchez ${ }^{b}$, Manuel Alberteris \\ Campos ${ }^{c}$, Linilson Padovese ${ }^{c}$, Hélio Goldenstein ${ }^{a}$ \\ ${ }^{a}$ Department of Metallurgical and Materials Engineering, Escola Politécnica, Universidade de São \\ Paulo-USP, Av. Prof. Mello Moraes 2463, 05508-030, SP, Brazil \\ ${ }^{b}$ Departamento de Física, Facultad de Ciencias Naturales, Universidad de Oriente, Av. Patricio \\ Lumumba, s/n, 90500, Santiago de Cuba, Cuba \\ 'Department of Mechanical Engineering, Escola Politécnica, Universidade de São Paulo - USP, Av. \\ Prof. Mello Moraes 2231, 05508-900, SP, Brazil \\ ${ }^{d}$ Professional School of Materials Engineering, University of San Agustin of Arequipa, Av. Venezuela, \\ $S / N$, Arequipa, Perú
}

Received: November 25, 2015; Revised: May 15, 2016; Accepted: July 8, 2016

\begin{abstract}
Duplex stainless steels have a structure normally composed of austenite and ferrite in approximately equal proportions. In order to attain control of its fabrication processes and performance, it is important to understand its microstructural evolution, due to the formation of intermetallic phases such as sigma $(\sigma)$ and chi $(\chi)$, which may cause a severe deterioration of mechanical properties. In the present study, the evolution of sigma phase during heat treatments at temperatures in which intermetallic phases can be formed $\left(800^{\circ} \mathrm{C}-900^{\circ} \mathrm{C}\right)$ was studied using magnetic analyses on a SAF2205 (DIN 1.4462/UNS S31803) steel. A significant reduction of the intensity of Magnetic Barkhausen Noise (MBN) was observed with the increase of heat treatment time, indicating a decrease in the quantity of ferromagnetic phases. For 24-hour-long treatments, the Barkhausen Noise signal is almost completely enclosed by the background noise, indicating the existence of a very small volume fraction of ferrite. If proper calibration samples are to be produced, this technique may be a viable method for non-destructive evaluation of field components working under thermal conditions that may cause the formation of intermetallic phases.
\end{abstract}

Keywords: Magnetic Barkhausen noise (MBN); Duplex stainless steels; Sigma phase; Nondestructive testing; Feritscope

\section{Introduction}

Duplex Stainless Steels (DSS) usually combines corrosion resistance with interesting mechanical properties. Their microstructure is normally composed of approximately equal fractions of austenite and ferrite. However, depending of the thermal cycles to which the steel is submitted, brittle undesirable phases may occur. Welding and hot forming operations are likely to cause harmful microstructural alterations, such as the formation of sigma $(\sigma)$ and chi $(\chi)$ phases, or chromium nitrides $\left(\mathrm{CrN}\right.$ and $\left.\mathrm{Cr}_{2} \mathrm{~N}\right)$. In particular, sigma phase, which is paramagnetic, may be studied using magnetic measurements whenever it forms by a decomposition reaction of the ferromagnetic ferrite, causing a decrease in the amount of ferromagnetic constituents.

Since $\sigma$ is the intermetallic phase more prominently formed during field applications of duplex stainless steel, its formation has been the object of several studies throughout the years, mostly focused on morphology and formation kinetic ${ }^{1-8}$, as well as its effects on mechanical properties ${ }^{9-11}$ and corrosion resistance ${ }^{12-17}$. Processes that include high temperature thermal cycling, such as welding, are particularly critical regarding the appearance of $\sigma$, due to the temperature range to which the heat affected zone is exposed in a poorly controlled manner. Thus, a method to evaluate the presence of sigma after such operations, even if qualitatively, is of great technological importance, especially if it can be used in field conditions and non-destructively.

Magnetic Barkhausen Noise (MBN) is based on the detection of a signal generated in ferromagnetic materials submitted to an external magnetic field. The signal is originated by the movement of magnetic domain walls, caused by the action of the external oscillating magnetic field. The signal detection occurs by induction of electric currents in a sensor coil.

The domain walls do not immediately follow changes in the magnetic field, as they encounter a resistance due to dissipative barriers. Thus, when a group of domain walls finally moves, it occurs abruptly and irreversibly. The internal energy of the systems rises, causing the emission of sudden peaks or magnetic field pulses. These field variations cause inducted voltage pulses in a sensor coil placed on the surface of the sample. These voltage pulses are referred to as Magnetic Barkhausen Noise, in honor of Heinrich Barkhausen, who discovered this phenomenon in 1919. 
Second phase particles, grain boundaries, dislocations and stress fields are effective barriers for the movement of the domain walls. For this reason, MBN is sensitive to microstructure, plastic and elastic strains in ferromagnetic materials ${ }^{18-21}$. It is also heavily influenced by defects such as porosity, inclusions, dislocations, pinning of punctual imperfections and stresses present ${ }^{22,23}$. Crystallographic texture may also have an influence on the intensity of the MBN signal, as it is widely known that certain orientations are more susceptible to magnetization than others.

Since sigma phase is not ferromagnetic, and formed by consumption of ferrite, its likely presence should be easily detected by magnetic measurements (it should be noticed that, without destructive testing, the decrease in magnetic signal cannot be uniquely attributed to sigma formation, since other non-ferromagnetic phases may form simultaneously, such as chi and nitrides)

The use of non-destructive methods to evaluate the formation of sigma phase has been reported before by several authors. Normando et al. ${ }^{24}$ used different non-destructive techniques to evaluate the formation of sigma after heat treatments conducted at 800 and $900^{\circ} \mathrm{C}$. The authors reported that the combination of different non-destructive techniques coupled with data processing procedures allowed for the identification of signals coming from samples with different amounts of sigma. Ginsztler et al..$^{25}$, compared potentiostatic etching and magnetic methods, and reported that Barkhausen noise measurements are accurate tools to evaluate the amount of ferromagnetic phase in superferritic stainless steels. Dobránszky et al. ${ }^{26}$ also showed the efficiency of Barkhausen noise as a method to evaluate the decrease in ferrite fraction in a superduplex stainless steel.

\section{Experimental Procedures}

\subsection{Material}

The steel used in the present study is a duplex stainless steel type DIN 1.4462 (UNS S31803). The chemical composition of the steel is presented in table 1. It was provided in rolled, rectangular section bars, with a microstructure composed of austenite fibers aligned along the rolling direction, approximately equiaxial in a transverse section, embedded in a ferrite matrix. The microstructure of the as received material is shown in figure 1 . The volume fraction of ferrite was measured by quantitative metallography. The measured values are given in table 2 . The sample was submitted to Electron Backscatter Diffraction analysis for evaluation of texture in the as-received condition. The orientation map for the as-received material is shown in figure 2 . The ferrite phase has a weak $\{001\}<\mathrm{uvw}>$ texture. No texture was detected in the austenite phase.
Table 1. Chemical composition of the steel used in this study.

\begin{tabular}{lcccccc}
\hline $\mathrm{C}$ & $\mathrm{Si}$ & $\mathrm{Mn}$ & $\mathrm{P}$ & $\mathrm{S}$ & $\mathrm{Co}$ & $\mathrm{Cr}$ \\
\hline 0.016 & 0.66 & 0.62 & 0.009 & 0.0016 & 0.03 & 22.60 \\
\hline $\mathrm{Mo}$ & $\mathrm{Ni}$ & $\mathrm{V}$ & $\mathrm{Cu}$ & $\mathrm{Al}$ & $\mathrm{B}$ & $\mathrm{N}$ \\
\hline 3.06 & 4.73 & 0.02 & 0.07 & 0.013 & 0.0031 & 0.20 \\
\hline
\end{tabular}

\subsection{Heat treatments and metallographic characterization}

A phase map as a function of temperature was calculated using ThermoCalc ${ }^{\circledR}$ software and the TCFE database, in order to choose the temperatures at which the heat treatments for formation of intermetallic phases would be done. Calculations were done taking into account the following elements: $\mathrm{Fe}$, $\mathrm{Cr}, \mathrm{Ni}, \mathrm{Mo}, \mathrm{Cu}, \mathrm{N}, \mathrm{C}, \mathrm{Si}$ and $\mathrm{Mn}$; and phases: Liquid, ferrite, austenite, $\mathrm{Cr}_{2} \mathrm{~N}, \sigma$ and $\mathrm{M}_{23} \mathrm{C}_{6}$. The calculated phase maps are presented in figure 3. Based on the calculated phase maps and on previous studies on sigma phase formation kinetics (e.g., references 3 and 4), the treatment temperatures of $800^{\circ} \mathrm{C}$ and $900^{\circ} \mathrm{C}$ were determined to be the most adequate ones. Although the phase map shows no formation of sigma at $900^{\circ} \mathrm{C}$, it must be kept in mind that the map refers to equilibrium conditions, which are not attained in real conditions. Extensive formation of sigma phase was reported in a previous study by one of the authors ${ }^{27}$ using this very same material. The treatments were conducted for $1 \mathrm{~h}, 8 \mathrm{~h}$ and $24 \mathrm{~h}$, followed by water quench. All heat treatments were conducted under vacuum, to prevent oxidation and nitrogen depletion near the surface. The samples used were $30 \times 30 \times 3 \mathrm{~mm}$ pieces, with the rolling direction parallel the $30 \times 30 \mathrm{~mm}$ face, as shown in figure 4 .

All samples (as-received and heat treated) were sectioned and polished down to $1 \mu \mathrm{m}$ diamond using standard metallographic procedures. Etching was done using the tint etch described by Beraha and Shpigler ${ }^{28}$ composed of $70 \mathrm{~mL}$ of distilled water, $30 \mathrm{~mL}$ of fuming hydrochloric acid and 1-2 $\mathrm{g}$ of potassium metabissulfite $\left(\mathrm{K}_{2} \mathrm{~S}_{2} \mathrm{O}_{5}\right)$ for each $100 \mathrm{~mL}$ of solution. As a result, ferrite is brown or blue (depending on orientation and thickness of the deposited film), austenite is lightly etched (slightly yellow), and sigma remains unetched, allowing for unequivocal identification due to its bright white aspect. The volume percent of the sigma phase of the samples were analysed using "Image J" image analysis software.

\subsection{Barkhausen noise measurements}

The acquisition of the Barkhausen signal was done using excitation by a sinusoidal magnetic wave of $10 \mathrm{~Hz}$, and a magnetic field of $\pm 1.2 \times 10^{4} \mathrm{~A} / \mathrm{m}$. A pickup coil, placed perpendicular to the sample surface. The acquired signal was amplified and band pass filtered $(1-150 \mathrm{kHz})$. The sampling frequency was $400 \mathrm{kHz}$. A schematic of the experimental setup for acquisition of the Barkhausen signal is given in figure $5^{29,30}$. 


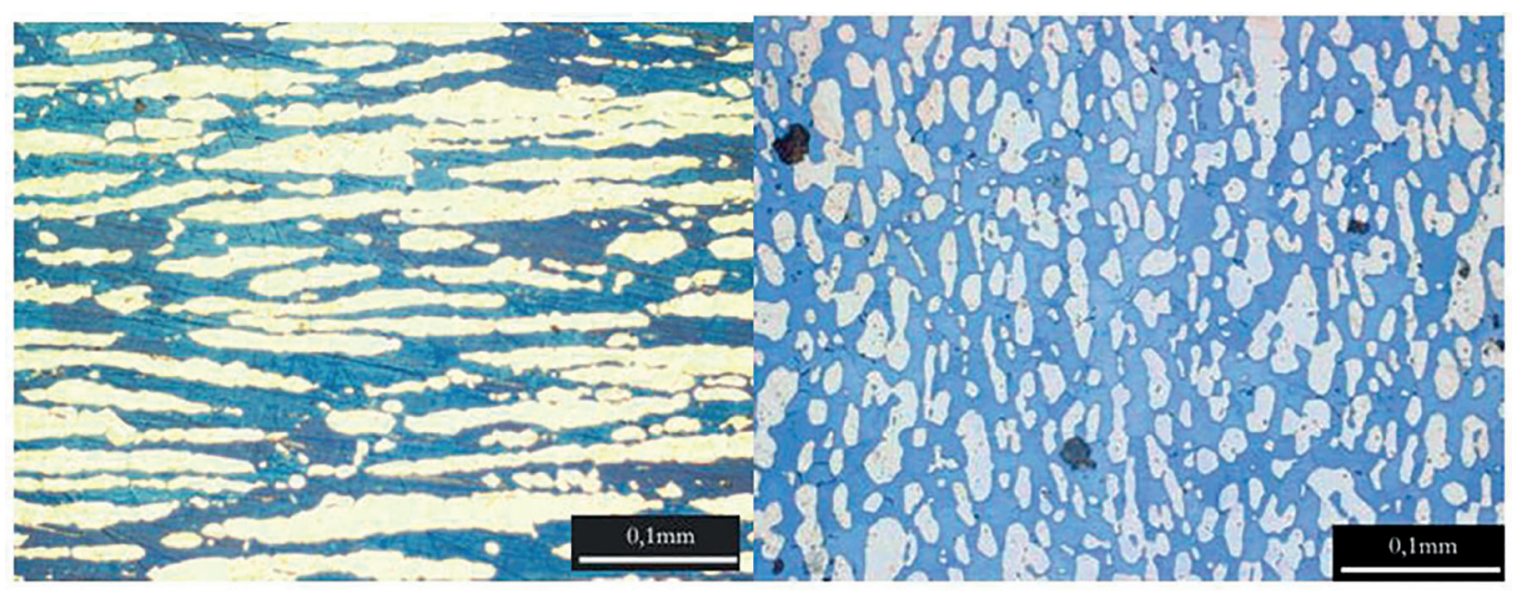

(a)

(b)

Figure 1. As-received condition of the material used in this study; a) parallel to rolling direction; b) transverse direction.

Table 2. Volume fractions of ferrite measured by quantitative metallography.

\begin{tabular}{lc}
\hline Direction & Ferrite volume fraction \\
\hline Rolling Direction & $53.1 \%$ \\
Normal Direction & $58.8 \%$ \\
\hline
\end{tabular}

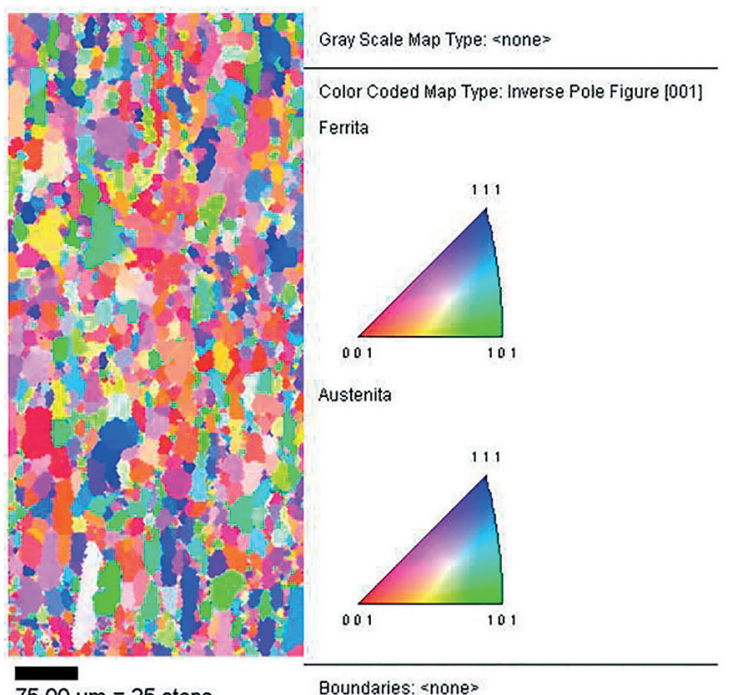

$75.00 \mu \mathrm{m}=25$ steps

Boundaries: «none»

Figure 2. Orientation map of the as received material.

The RMS (Root Mean Square) voltage of the Barkhausen signal is defined by equation 1 as:

$$
R M S=\sqrt{\frac{\sum^{i} V_{i}^{2}}{n}} \text { eq.1 }
$$

In which $\mathrm{V}_{\mathrm{i}}$ is the voltage of each signal individual peak and $\mathrm{n}$ is the total number of evented detected in a single measurement. The RMS voltage was then averaged over ten measurements ${ }^{30}$. By defining a bottom voltage level, the noise not belonging to the Barkhausen signal was eliminated from the MBN measurements. This threshold is determined by taking a time window with the background noise only and, then, calculating the RMS of this noise. Only those $\mathrm{MBN}$ voltages having amplitude higher than this threshold are considered for analysis.

\subsection{Feritscope Measurements}

In this work, a Feritscope MP30 (Fischer) was used to determinate the volume fraction of $\alpha-\mathrm{Fe}$ (ferrite). The Feritscope is a commercially available device that has been developed for the non-destructive measurements of the ferrite content in austenitic and duplex steels in the range of 0.1 to $80 \% \alpha-\mathrm{Fe}$.

\section{Results and Discussion}

Microstructures of the samples submitted to heat treatment are shown in figures 6 and 7. It can be clearly seen in all micrographs that the formation of sigma phase takes place by consumption of ferrite. As the reaction progresses, the fraction of ferromagnetic phase (ferrite) diminishes considerably and one expects that, as a result, the intensity of the Barkhausen noise also should diminish in a corresponding manner. It can also be seen that, for longer treatment times at $800^{\circ} \mathrm{C}$, the reaction is very advanced, and there are regions in which the ferrite has already been entirely consumed. At $900^{\circ} \mathrm{C}$, however, the reaction is not nearly as advanced after 24 hours as it is at $800^{\circ} \mathrm{C}$, indicating that the "nose" of the C-curve that characterizes sigma formation kinetics is below $900^{\circ} \mathrm{C}$ (this will be further addressed in the "Barkhausen Measurements" section). The morphology of formed sigma phase does not follow typical characteristics of cooperative growth, such 


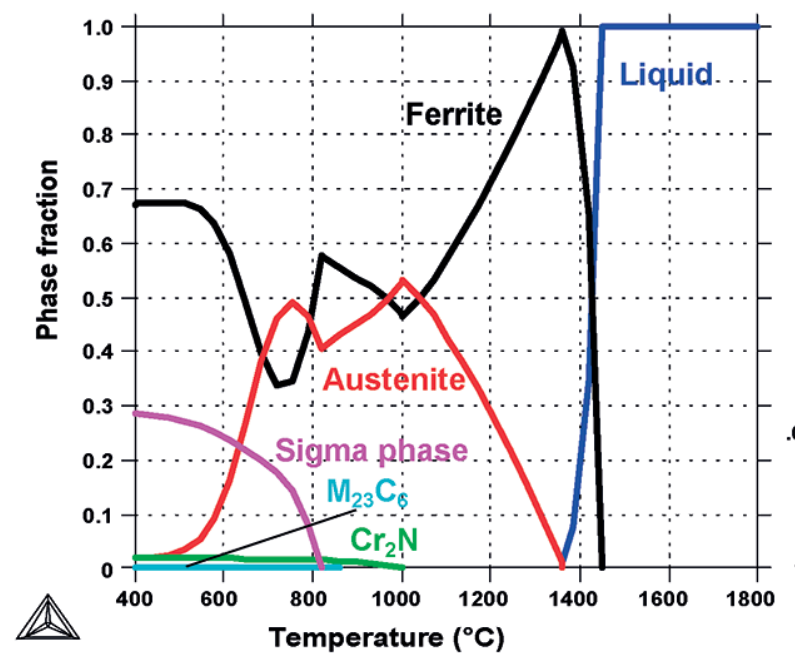

(a)

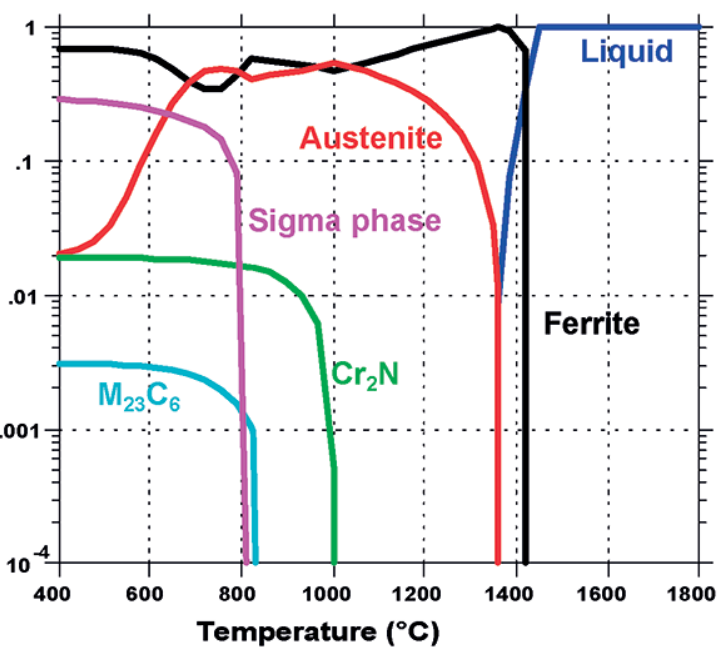

(b)

Figure 3. Calculated phase map (Mass fraction) for the material used in the present study as a function of temperature; a) Phase fraction in linear scale; b) phase fraction in log scale.

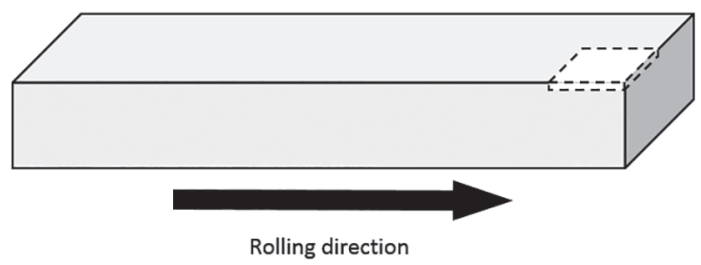

Figure 4. Schematic of sample extraction from the as received bar.

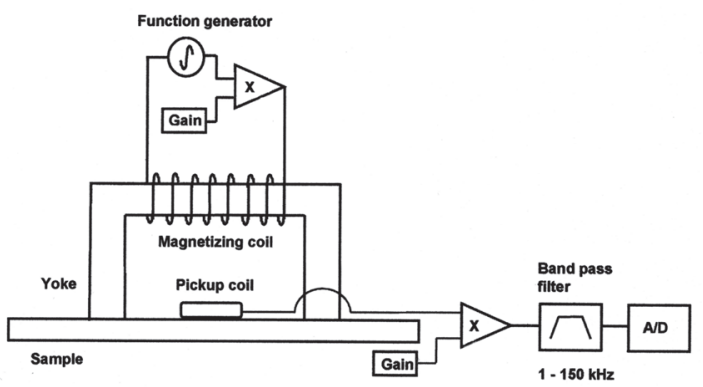

Figure 5. Experimental setup for acquisition of Barkhausen Noise ${ }^{29,30}$.

as lamellar structures, and it is possible that small fractions of untransformed ferrite are trapped inside sigma colonies, which makes it possible that even after long treatment times some Barkhausen signal may be detected at slightly higher levels than the background noise.

\subsection{Barkhausen noise measurements}

The characteristic signal Barkhausen signal for the as received condition is shown in figure 8 . As a consequence of the more than $50 \%$ volume fraction of ferrite, the signal-tonoise ratio found is quite strong. The Barkhausen noise signals of heat-treated samples are given in figures $9\left(800{ }^{\circ} \mathrm{C}\right)$ and $10\left(900^{\circ} \mathrm{C}\right)$. It is clearly noticeable that the signal intensity is much higher in the as-received sample than in the heattreated ones. While the maximum voltage value observed in the as-received condition is close to $2 \mathrm{~V}$, the highest voltages even for samples treated for $1 \mathrm{~h}$ is approximately $0.5 \mathrm{~V}$, indicating a strong decrease in intensity even for very small quantities of sigma. The variation of the intensity of RMS signal with time is shown in figures 11 to 13 . The decrease of signal intensity is much steeper for smaller times, and the proportional decrease ( $24 \mathrm{~h}$ compared to $8 \mathrm{~h}$ ) becomes very slight over time, indicating that the major part of the transformation has already taken place after 8 hours.

The decrease in Barkhausen signal is smaller at $900^{\circ} \mathrm{C}$. This is due to a kinetic issue. The formation of sigma phase follows a classic $\mathrm{C}$-type curve. The nose of the sigma $\mathrm{C}$-curve for this steel is at approximately $850^{\circ} \mathrm{C}$, as reported by Magnabosco ${ }^{4}$ in a previous study. Therefore, the treatments at $900^{\circ} \mathrm{C}$ lies above the nose and a slower kinetic is expected. Based on the TTT curve presented by Magnabosco $0^{4}$, the time it takes to attain a $40 \%$ volume fraction of sigma at $900^{\circ} \mathrm{C}$ is 10 times longer than at $800^{\circ} \mathrm{C}$. It should be remembered that above the nose of the $\mathrm{C}$-curve, the decrease in reaction kinetics can be quite significant even for small variations of treatment temperature. The sample treated at $800^{\circ} \mathrm{C}$ was slightly below the nose, and the reaction kinetics is indeed expected to be significantly faster than at $900^{\circ} \mathrm{C}$.

The decrease of the volume fraction of $\alpha$-Fe (ferrite) in the Feritscope MP30 (Fischer) in treatments for 1, 8 and 24 h, at 800 and $900{ }^{\circ} \mathrm{C}$ are shown in Figures 12 and 13. The 


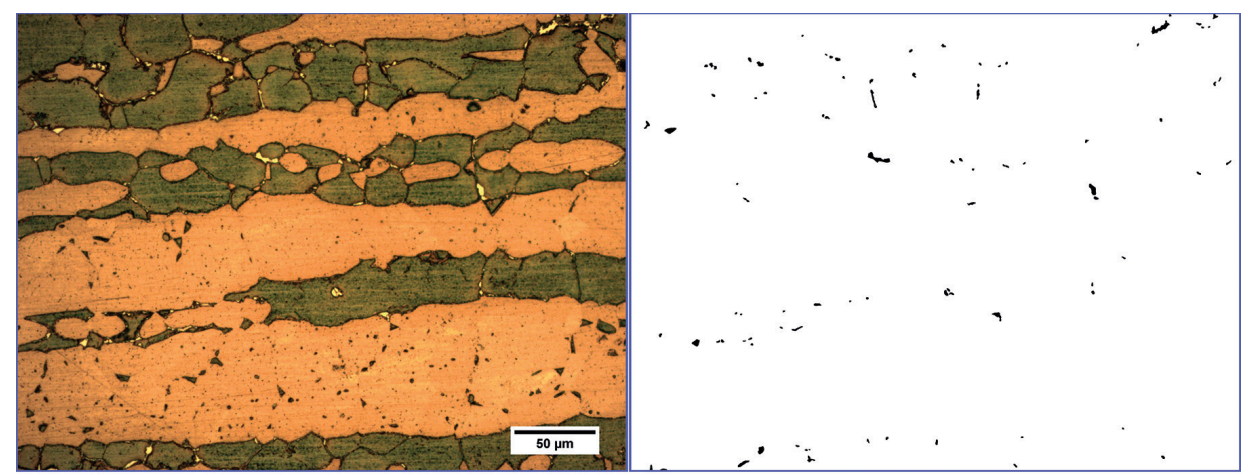

(a)

(b)

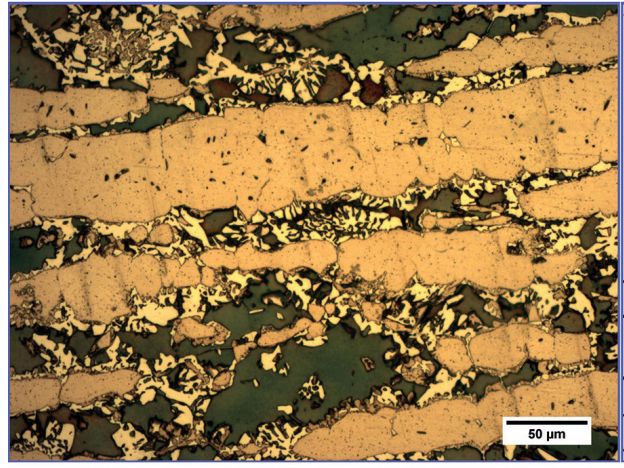

(c)

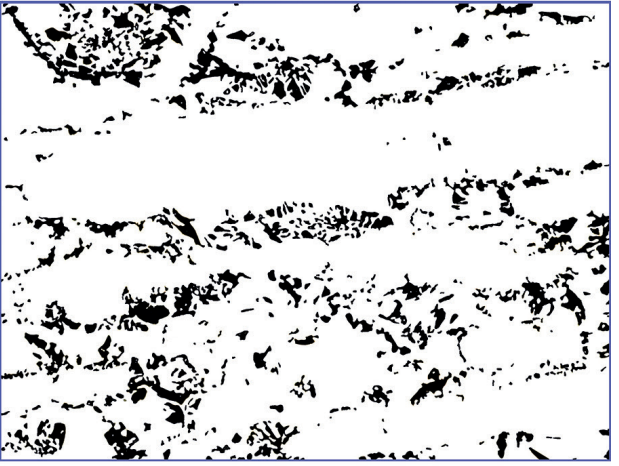

(d)

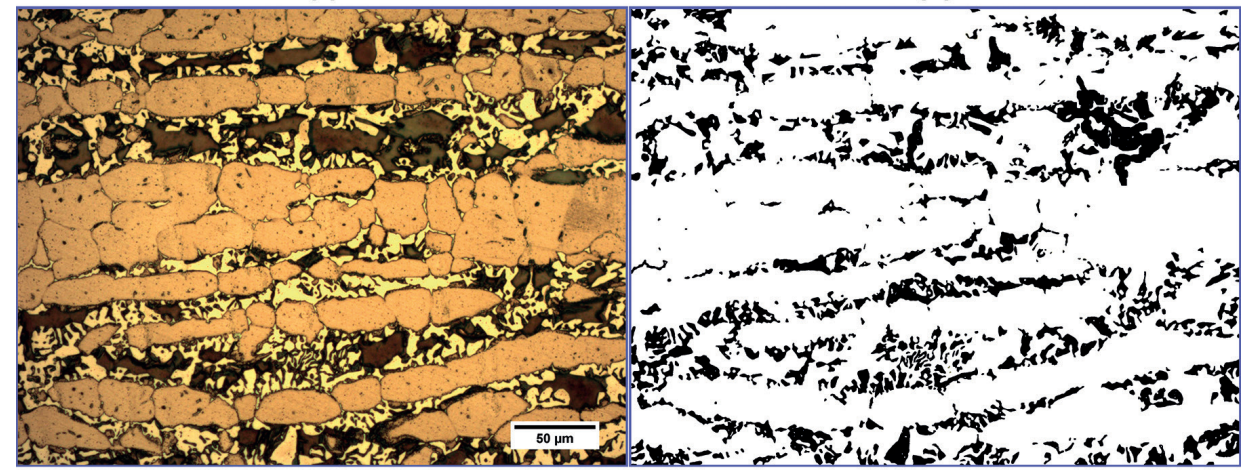

(e)

(f)

Figure 6. Micrographs and binary separation of sigma phase (sigma is black in the binary images) of samples treated at $800^{\circ} \mathrm{C}-\mathrm{a}$ ) optical micrograph, 1h; b) binary separation of sigma, 1h; c) optical micrograph, 8h; d) binary separation of sigma, 8h; e) optical micrograph, $24 \mathrm{~h} ; \mathrm{f}$ ) binary separation of sigma, $24 \mathrm{~h}$.

decrease in ferrite volume fraction is attributed not only to the increase of sigma phase, but also to other paramagnetic or less ferromagnetic phases, as nitrides, chromium carbides and especially the secondary austenite. These phases are also harmful to the corrosion resistance of the steel, since some of them are chromium traps, and reduce the availability of chromium for the formation of the passive layer.

The kinetics of sigma formation measured in this study is consistent with that reported by Magnabosco ${ }^{4}$ and with the results of Elmer et al. ${ }^{2}$ obtained using In-situ Synchrotron X-Ray Diffraction. More important than the kinetic measurements, however, is the indication that the Barkhausen noise signal can be adequately used to assess the decrease in ferromagnetic phase over time, thus making it a valuable non-destructive technique.

The correspondence between the microstructure and the magnetic response of stainless steels, including its variation during phase transformations, was the object of a series of studies by Tavares and co-workers ${ }^{31-33}$. Their work was done using measurements of saturation magnetization, remanence, coercive force and magnetic transition temperature, and included the magnetic response as a function of ferrite/austenite proportion $^{31}$, high and low temperature embrittlement ${ }^{32}$ and specific measurements aimed at sigma phase formation ${ }^{33}$. In the latter case, the Ferritscope and Magnetic saturation 


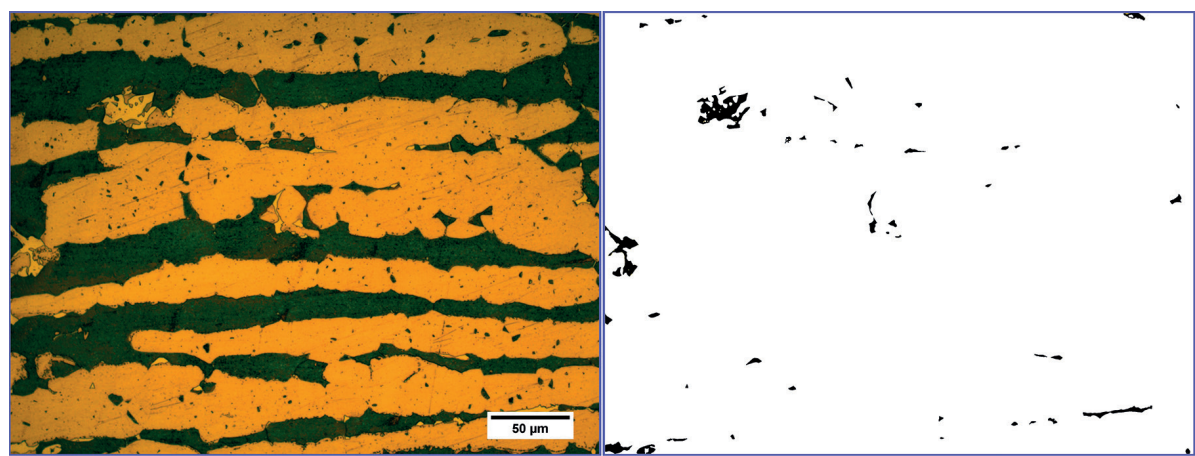

(a)

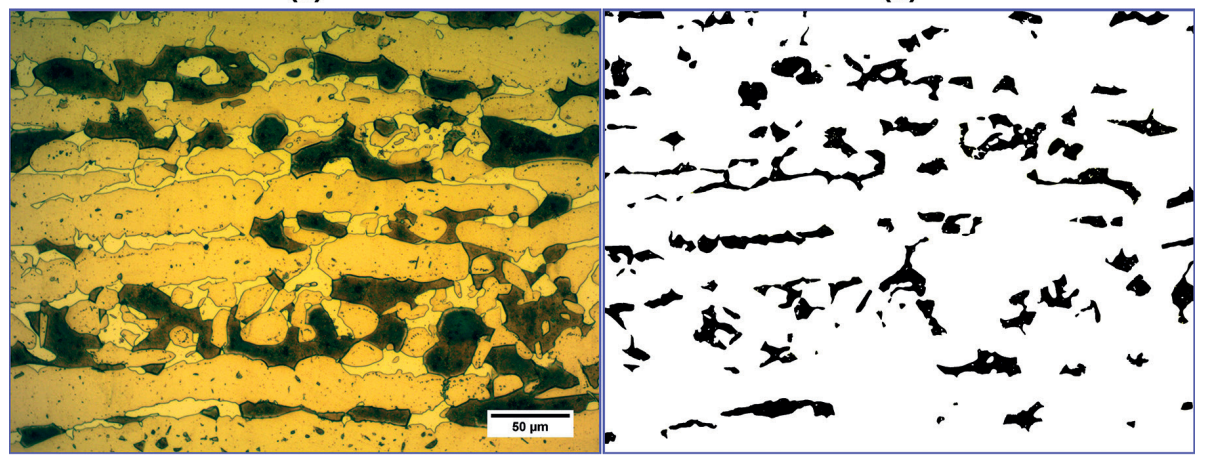

(c)

(d)

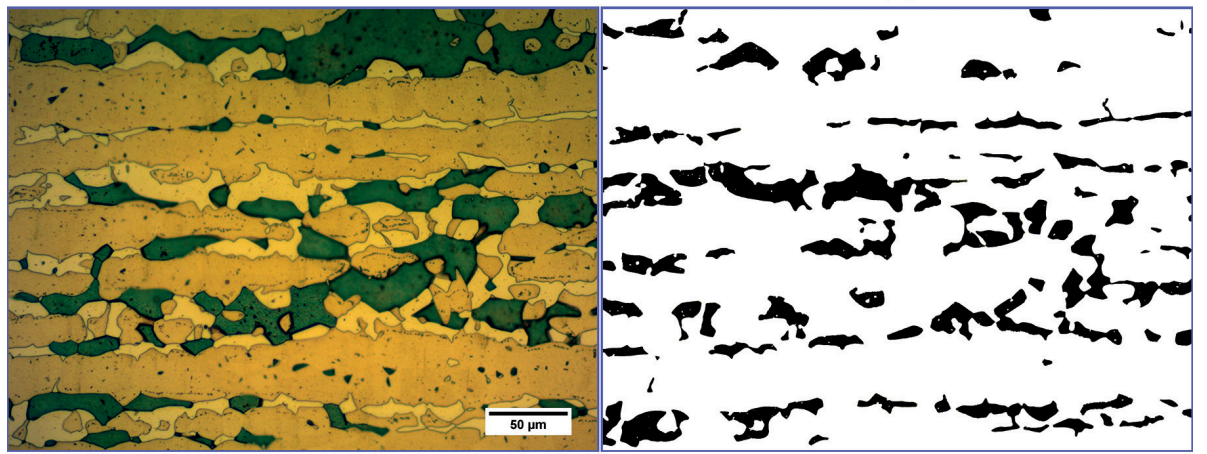

(e)

(f)

Figure 7. Micrographs and binary separation of sigma phase (sigma is black in the binary images) of samples treated at $900^{\circ} \mathrm{C}-\mathrm{a}$ ) optical micrograph, 1h; b) binary separation of sigma, 1h; c) optical micrograph, 8h; d) binary separation of sigma, 8h; e) optical micrograph, $24 \mathrm{~h} ; \mathrm{f}$ ) binary separation of sigma, $24 \mathrm{~h}$.

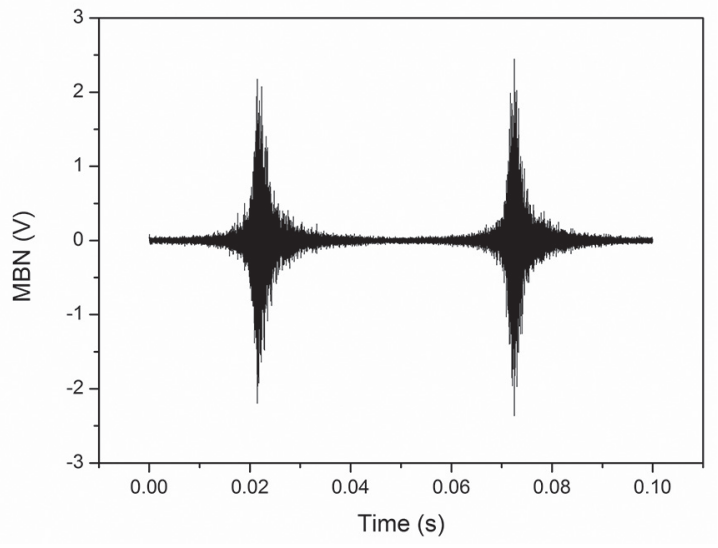

Figure 8. Barkhausen noise of the as received sample. measurements were used, and the authors observed that both methods are sensitive to small fractions of sigma.

Mezaros and $\mathrm{Szabo}^{34}$ also reported the change of magnetic parameters that takes place with the change in ferromagnetic phase volume fraction. The authors, however, did not try to associate a variation in ferrite fraction with the magnetic response measured. Instead, the change was measured as a function of heat treatment temperature. The magnetic measurements based on maximum magnetic permeability showed a linear relation when compared to Vickers hardness measurements. It must be noted, though, that several characteristics that are affected by the heat treatment may influence the hardness value, and they affect the Barkhausen noise signal in different ways. The authors noted that a 


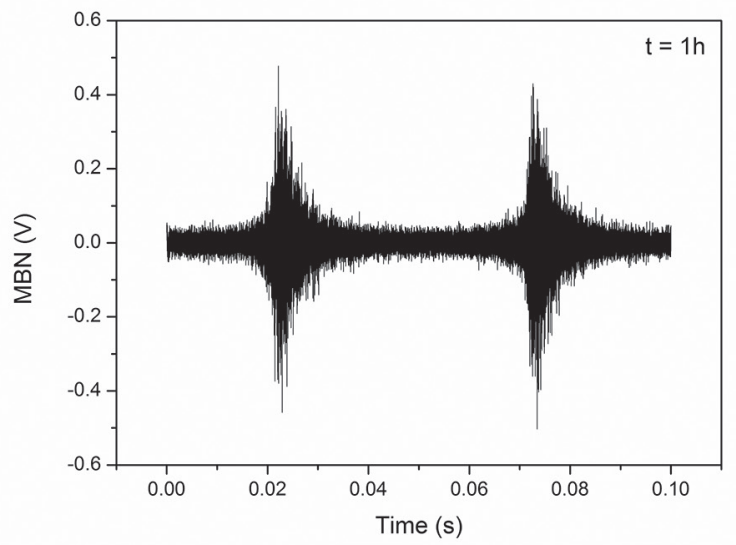

(a)

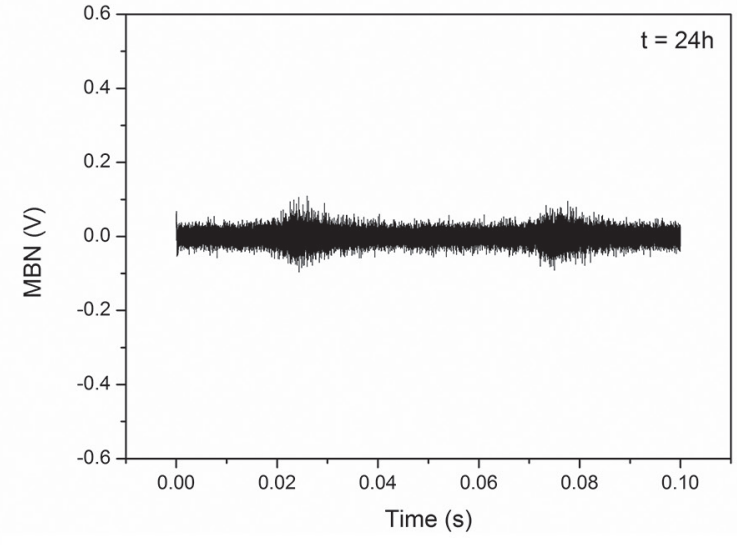

(b)

Figure 9. Barkhausen noise of samples treated at $800^{\circ} \mathrm{C}-$ a) $1 \mathrm{~h}$; b) $24 \mathrm{~h}$.

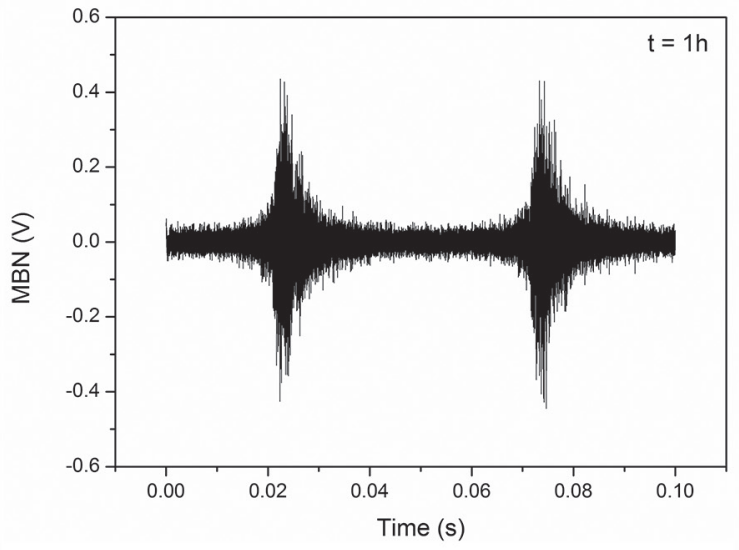

(a)

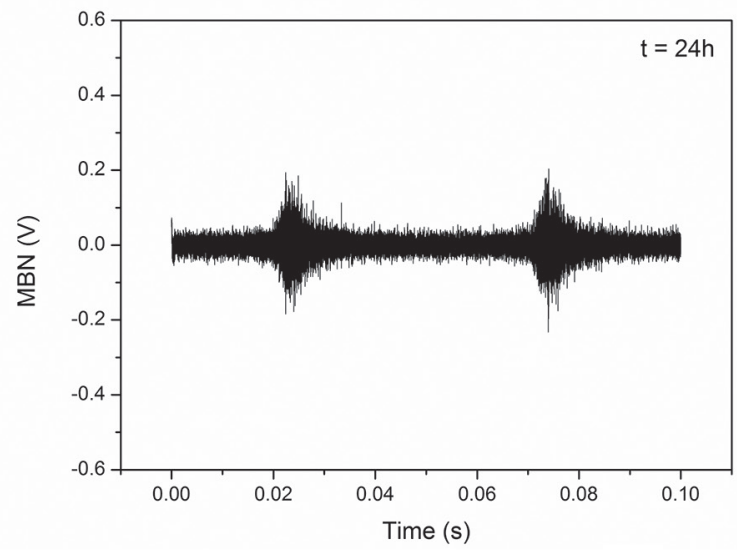

(b)

Figure 10. Barkhausen noise of samples treated at $900^{\circ} \mathrm{C}-$ a) $1 \mathrm{~h}$; b) $24 \mathrm{~h}$.

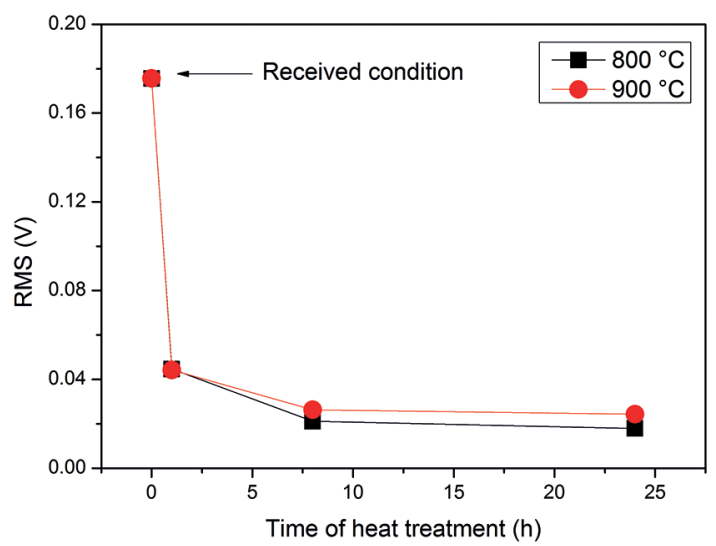

Figure 11. Variation of the intensity of Barkhausen Noise signal with time during isothermal hold at $800^{\circ} \mathrm{C}$ and $900^{\circ} \mathrm{C}$ (includes as received condition).

correlation between Barkhausen Noise and hardness is not a reliable one. However, the correlation with microstructure is much more straightforward. Ginsztler et al. ${ }^{25}$ pointed out the

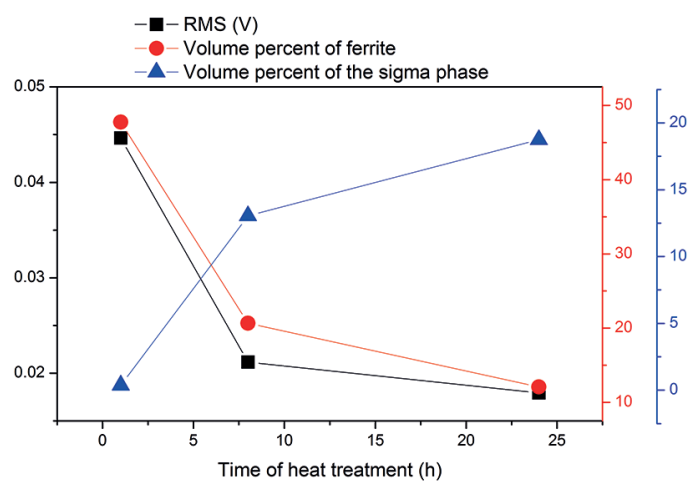

Figure 12. Variation of the intensity of Barkhausen Noise signal (RMS), Ferrite volume percent (measured with Fischer feritscope) and Volume percent of the sigma phase (measured with metallography) with time during isothermal hold at $800{ }^{\circ} \mathrm{C}$.

direct correlation that can be made between the Barkhausen noise signal profile and the amount of ferromagnetic phase. The results presented here are in good agreement with those 


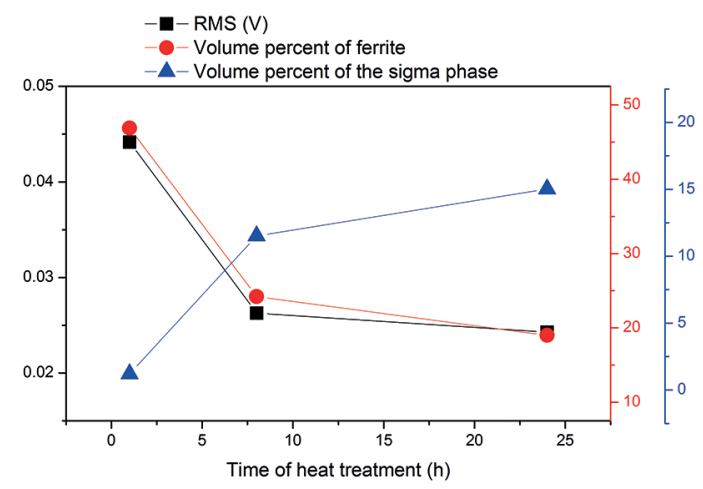

Figure 13. Variation of the intensity of Barkhausen Noise signal (RMS), Ferrite volume percent (measured with Fischer feritscope) and Volume percent of the sigma phase (measured with metallography) with time during isothermal hold at $900{ }^{\circ} \mathrm{C}$.

presented by Ginsztler et al. ${ }^{25}$ Also, the results presented confirm the observations of Normando et al. ${ }^{24}$, that sigma phase formation can be accurately followed using only non-destructive techniques, which allows for inspections of facilities in the field. However, a calibration curve (corresponding microstructure vs. Barkhausen noise signal) is critical to perform accurate microstructural evaluations using Barkhausen Noise as a non-destructive technique.

Blaow et al. ${ }^{19}$ pointed out that microstructures in carbon steels associated with magnetic softness were associated with higher peaks. Also, these authors reported that the presence of strain might lead to a separation of the Barkhausen signal peak into three different peaks. Based on this result, it is possible to state that, in the present study, sigma formation takes place without the onset of significant elastic strain during the reaction.

The results presented here are in good agreement with the aforementioned works, and present a clear indication that Magnetic Barkhausen Noise is a technique that can be used for non-destructive evaluation of microstructural changes taking place in duplex stainless steels during field service. Using the measured volume fraction of ferrite obtained from samples treated at various times, a calibration curve can be plotted, relating the fraction of ferrite and sigma phase as a function of the intensity of magnetic noise signal. It must be kept in mind, though, that sigma is not the only phase that can be formed at high temperatures. The magnetic measurements will only point out the decrease in ferrite content, without giving any clues on the products formed or what reaction mechanism is taking place. Chromium nitrides and chi phase, for example, may be formed, but only the ferrite decrease will be detected. In order to know what phases are likely formed, other classical studies (metallographic evaluation and quantification of phases) are needed. Based on the decrease of ferrite content, and aided by kinetic studies, it should be possible to estimate the amount of sigma plus other phases based on Magnetic Barkhausen noise. Besides the estimation of the amount of phases present, the correct calibration of the magnetic noise curves as a function of microstructure will also allow for the capture of a magnetic noise intensity curve that describes the progress of the decomposition of ferrite into $\sigma$ and austenite, thus allowing for in situ estimation of predicted life of components subjected to work conditions in which the formation of intermetallic phases may take place. The same principle used in this study to evaluate the formation of sigma phase could also be used to evaluate reactions leading to other phases in different work conditions.

\section{Conclusions}

The progress of sigma phase formation during isothermal treatments conducted at $800^{\circ} \mathrm{C}$ and $900^{\circ} \mathrm{C}$ can be followed using magnetic measurements. The formation of sigma phase causes a measurable decrease in the intensity of Magnetic Barkhausen Noise.

The formation of small fractions of sigma phase can be detected using Magnetic Barkhausen Noise as a non-destructive evaluation, and the method presents high sensitivity over time.

A calibration curve can be plotted relating the fraction of ferrite and sigma phase as a function of the magnetic signal intensity. This curve can be used as a non-destructive evaluation method in industrial environments.

\section{Acknowledgements}

The authors are grateful to Brazilian Research Incentive agencies (CNPq, CAPES and FAPESP) for financial support.

\section{References}

1. Cortie MB, Jackson EMLEM. Simulation of the precipitation of sigma phase in duplex stainless steels. Metallurgical and Materials Transactions A. 1997;28(12):2477-2484.

2. Elmer JW, Palmer TA, Specht ED. Direct observations of sigma phase formation in duplex stainless steels using in-situ synchrotron X-ray diffraction. Metallurgical and Materials Transactions A. 2007;38(3):464-475.

3. Sieurin H, Sandström R. Sigma phase precipitation in duplex stainless steel 2205. Materials Science and Engineering: A. 2007;444(1-2):271-276.

4. Magnabosco R. Kinetics of sigma phase formation in a duplex stainless steel. Materials Research. 2009;12(3):321-327.

5. Calliari I, Brunelli K, Dabalà M, Ramous E. Measuring secondary phases in duplex stainless steels. JOM The Journal of the Minerals, Metals \& Materials Society (TMS). 2009;61(1):80-83.

6. Martins M, Casteletti LC. Sigma phase morphologies in cast and aged super duplex stainless steel. Materials Characterization. 2009;60(8):792-795. 
7. Calliari I, Ramous E, Bassani P. Phase transformation in duplex stainless steels after isothermal treatments, continuous cooling and cold working. Materials Science Forum. 2010;638642:2986-2991.

8. Ferro P, Bonollo F. A Semiempirical Model for Sigma-Phase Precipitation in Duplex and Superduplex Stainless Steels. Metallurgical and Materials Transactions A . 2012;43(4):1109-1116.

9. Zucato I, Moreira MC, Machado IF, Lebrão SMG. Microstructural characterization and the effect of phase transformations on toughness of the UNS S31803 duplex stainless steel aged treated at $850^{\circ}$ C. Materials Research. 2002;5(3):385-389.

10. Kuroda T. Role of sigma phase on hydrogen embrittlement of super duplex stainless steels. Transactions of Japan Welding Research Institute. 2005;34(2):63-68.

11. Miodownik AP, Saunders N. Modelling of materials properties in duplex stainless steels. Materials Science and Technology. 2002;18(8):861-868.

12. Tavares SSM, Terra VF, De Lima Neto P, Matos DE. Corrosion resistance evaluation of the UNS S31803 duplex stainless steels aged at low temperatures $\left(350\right.$ to $\left.550^{\circ} \mathrm{C}\right)$ using DLEPR tests. Journal of Materials Science. 2005;40(15):4025-4028.

13. Ezuber HM, El-Houd A, El-Shawesh F. Effects of sigma phase precipitation on seawater pitting of duplex stainless steel. Desalination. 2007;207(1-3):268-275.

14. Moura VS, Lima LD, Pardal JM, Kina AY, Corte RRA, Tavares SSM. Influence of microstructure on the corrosion resistance of the duplex stainless steel UNS S31803. Materials Characterization. 2008;59(8):1127-1132.

15. Fargas G, Anglada M, Mateo A. Effect of the annealing temperature on the mechanical properties, formability and corrosion resistance of hot-rolled duplex stainless steel. Journal of Materials Processing Technology. 2009;209(4):1770-1782.

16. Han Y, Zou DN, Zhang W, Huang R. Sigma phase precipitation of duplex stainless steel and its effect on corrosion resistance. Materials Science Forum. 2009;620-622:391-394.

17. Kobayashi DY, Wolynec S. Evaluation of the low corrosion resistant phase formed during the sigma phase precipitation in duplex stainless steels. Materials Research. 1999;2(4):239-247.

18. Anglada-Rivera J, Padovese LR, Capó-Sanchez J. Magnetic Barkhausen Noise and hysteresis loop in commercial carbon steel: influence of applied tensile stress and grain size. Journal of Magnetism and Magnetic Materials. 2001;231(2-3):299-306.

19. Blaow M, Evans JT, Shaw BA. Magnetic Barkhausen noise: the influence of microstructure and deformation in bending. Acta Materialia. 2005;53(2):279-287.

20. Alberteris Campos M, Capó-Sánchez J, Pérez Benítez J, Padovese LR. Characterization of the elastic-plastic region in AISI/ SAE 1070 steel by the magnetic barkhausen noise. $N D T \& E$ International. 2008;41(8):656-659.
21. Hutanu R, Clapham L, Rogge RB. Intergranular strain correlation with magnetic behavior in steel. Applied Physics Letters. 2005;86(16):162503.

22. Rabung M, Altpeter I, Boller C, Dobmann G, Herrmann HG. Non-destructive evaluation of the micro residual stresses of IIIrd order by using micro magnetic methods. NDT \& $E$ International. 2014;63:7-10.

23. Kleber X, Vincent A. On the role of residual internal stresses and dislocations on Barkhausen noise in plastically deformed steel. NDT \& E International. 2004;37(6):439-445.

24. Normando PG, Moura EP, Souza JA, Tavares SSM, Padovese LR. Ultrasound, eddy current and magnetic Barkhausen noise as tools for sigma phase detection on a UNS S31803 duplex stainless steel. Materials Science and Engineering: A. 2010;527(12):2886-2891.

25. Ginsztler J, Mészáros I, Dévényi L, Hidasi B, Potgieter JH. Magnetic investigations of stainless steels. International Journal of Pressure Vessels and Piping. 1995;61(2-3):471-478.

26. Dobránszky J, Mészáros I, Gyula N. Mechanical and thermal induced phase transformations in superduplex stainless steel. In: 6th World Duplex Conference and Expo; 2002; Milan, Italy. Associazione Italiana di Metallurgia. p. 385-393.

27. Monlevade EF, Falleiros IGS. Orientation relationships associated with austenite formation from ferrite in a coarse-grained duplex stainless steel. Metallurgical and Materials Transactions A. 2006;37(3):939-949.

28. Beraha E, Shpigler B. Color metallography. Metals Park: American Society for Metals; 1977.

29. Capò Sànchez J, Huallpa E, Farina P, Padovese LR, Goldenstein H. Magnetic and spontaneous Barkhausen noise techniques used in investigation of a martensitic transformation. Journal of Applied Physics. 2011;110(8):083916.

30. Apaza Huallpa E, Capó Sánchez J, Padovese LR, Goldenstein H. Determining Ms temperature on a AISI D2 cold work tool steel using magnetic Barkhausen noise. Journal of Alloys and Compounds. 2013;577(Suppl 1):S726-S730.

31. Tavares SSM, Pedrosa PDS, Teodósio JR, da Silva MR, Neto JM, Pairis S. Magnetic properties of the UNS S39205 duplex stainless steel. Journal of Alloys and Compounds. 2003;351(1-2):283-288.

32. Tavares SSM, da Silva MR, Neto JM. Magnetic property changes during embrittlement of a duplex stainless steel. Journal of Alloys and Compounds. 2000;313(1-2):168-173.

33. Tavares SSM, Pardal JM, Guerreiro JL, Gomes AM, da Silva MR. Magnetic detection of sigma phase in duplex stainless steel UNS S31803. Journal of Magnetism and Magnetic Materials. 2010;322(17):L29-L33.

34. Mészáros I, Szabo PJ. Complex magnetic and microstructural investigation of duplex stainless steel. NDT \& E International. 2005;38(7):517-521. 